\title{
Dynamic development of the first synapse impinging on adult-born neurons in the olfactory bulb circuit
}

Hiroyuki Katagiri ${ }^{1,2}$, Marta Pallotto ${ }^{1,2,3}$, Antoine Nissant ${ }^{1,2}$, Kerren Murray $^{1,2}$, Marco Sassoè-Pognetto $^{3}$, Pierre-Marie Lledo ${ }^{1,2^{*}}$

\begin{abstract}
The olfactory bulb $(\mathrm{OB})$ receives and integrates newborn interneurons throughout life. This process is important for the proper functioning of the $O B$ circuit and consequently, for the sense of smell. Although we know how these new interneurons are produced, the way in which they integrate into the pre-existing ongoing circuits remains poorly documented. Bearing in mind that glutamatergic inputs onto local OB interneurons are crucial for adjusting the level of bulbar inhibition, it is important to characterize when and how these inputs from excitatory synapses develop on newborn $O B$ interneurons. We studied early synaptic events that lead to the formation and maturation of the first glutamatergic synapses on adult-born granule cells (GCs), the most abundant subtype of OB interneuron. Patch-clamp recordings and electron microscopy (EM) analysis were performed on adult-born interneurons shortly after their arrival in the adult $\mathrm{OB}$ circuits. We found that both the ratio of $\mathrm{N}$-methyl-D-aspartate receptor (NMDAR) to $\alpha$-amino-3-hydroxy-5-methyl-4-isoxazolepropionic acid receptor (AMPAR), and the number of functional release sites at proximal inputs reached a maximum during the critical period for the sensory-dependent survival of newborn cells, well before the completion of dendritic arborization. EM analysis showed an accompanying change in postsynaptic density shape during the same period of time. Interestingly, the latter morphological changes disappeared in more mature newly-formed neurons, when the NMDAR to AMPAR ratio had decreased and functional presynaptic terminals expressed only single release sites. Together, these findings show that the first glutamatergic inputs to adult-generated $\mathrm{OB}$ interneurons undergo a unique sequence of maturation stages.
\end{abstract}

\section{Background}

Adult neurogenesis, a process encompassing the generation, maturation and synaptic integration of new neurons in the adult brain, represents a striking form of structural adult neural plasticity [1-3]. In the adult olfactory bulb $(\mathrm{OB})$, nearly all newly recruited neurons become local interneurons [4]. About $95 \%$ of the new cells differentiate into granule cells (GCs) and less than $4 \%$ become periglomerular cells [5,6], with glutamatergic juxtaglomerular neurons accounting for the rest [7]. The newly-formed interneurons project dendrites that establish synaptic contacts with pre-existing partners,

\footnotetext{
* Correspondence: pmlledo@pasteur.fr

'Laboratory for Perception and Memory, Institut Pasteur, Paris, France
}

Full list of author information is available at the end of the article becoming indistinguishable from other mature interneurons within few weeks [8-13].

GCs are the largest population of interneurons in the bulb, outnumbering principal neurons by 100 to one [14]. Strikingly, they are also the most abundant subtype of neurons added to the adult OB [15]. GCs bear several short basal dendrites and one apical dendrite, which consists of a proximal domain and a branched distal domain (Figure 1A, Figure 2A). GCs form $\gamma$-aminobutyric acid (GABA)ergic output synapses onto the principal neurons, the mitral cells/tufted cells (MC/TCs), through dendrodendritic reciprocal contacts in the external plexiform layer [14]. In turn, they receive spatially segregated glutamatergic inputs at distinct dendritic sites $[13,16,17]$. Reciprocal dendrodendritic synapses with the $\mathrm{MCs}$ are the main source of distal glutamatergic input
Ciomed Central

() 2011 Katagiri et al; licensee BioMed Central Ltd. This is an Open Access article distributed under the terms of the Creative Commons Attribution License (http://creativecommons.org/licenses/by/2.0), which permits unrestricted use, distribution, and reproduction in any medium, provided the original work is properly cited. 


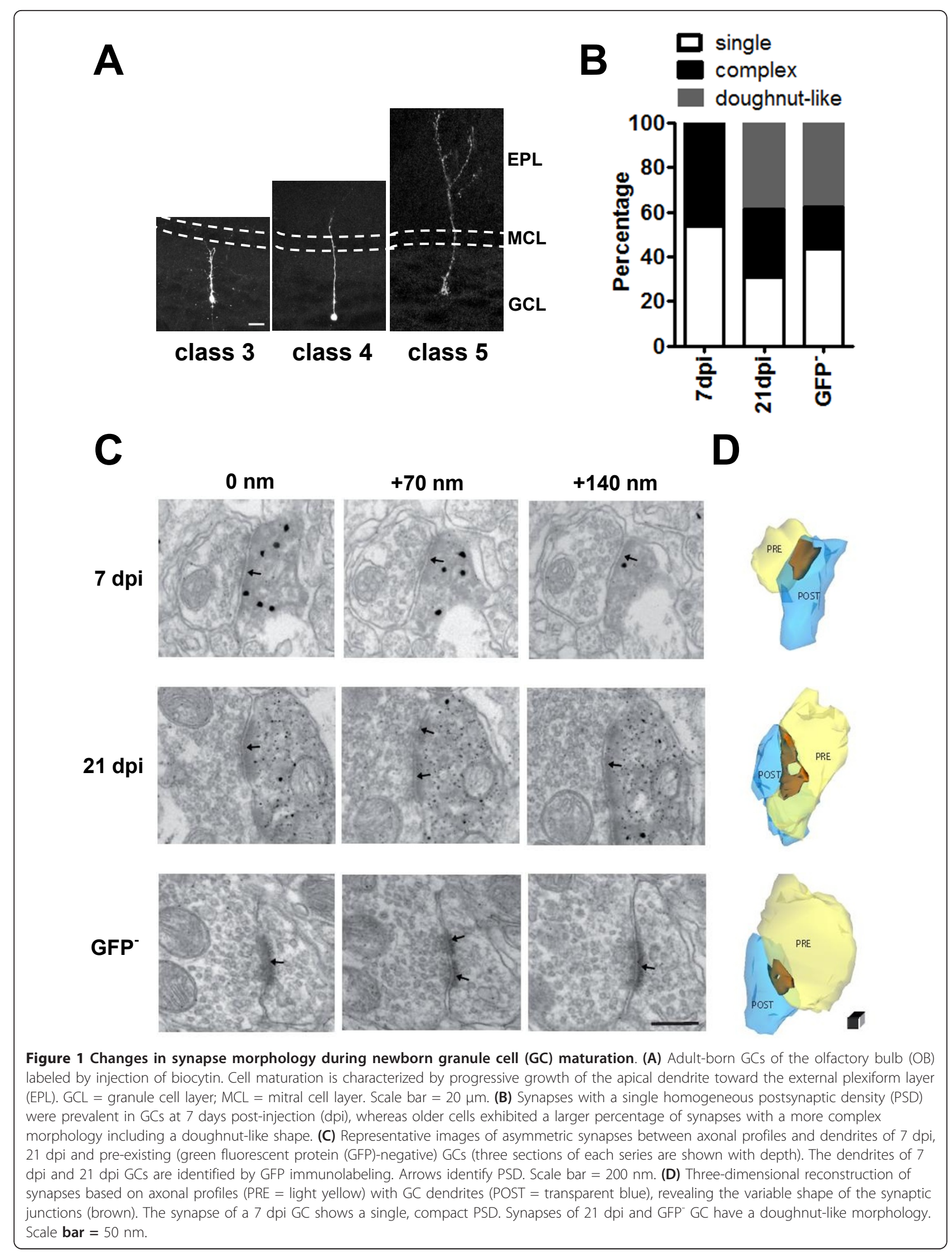




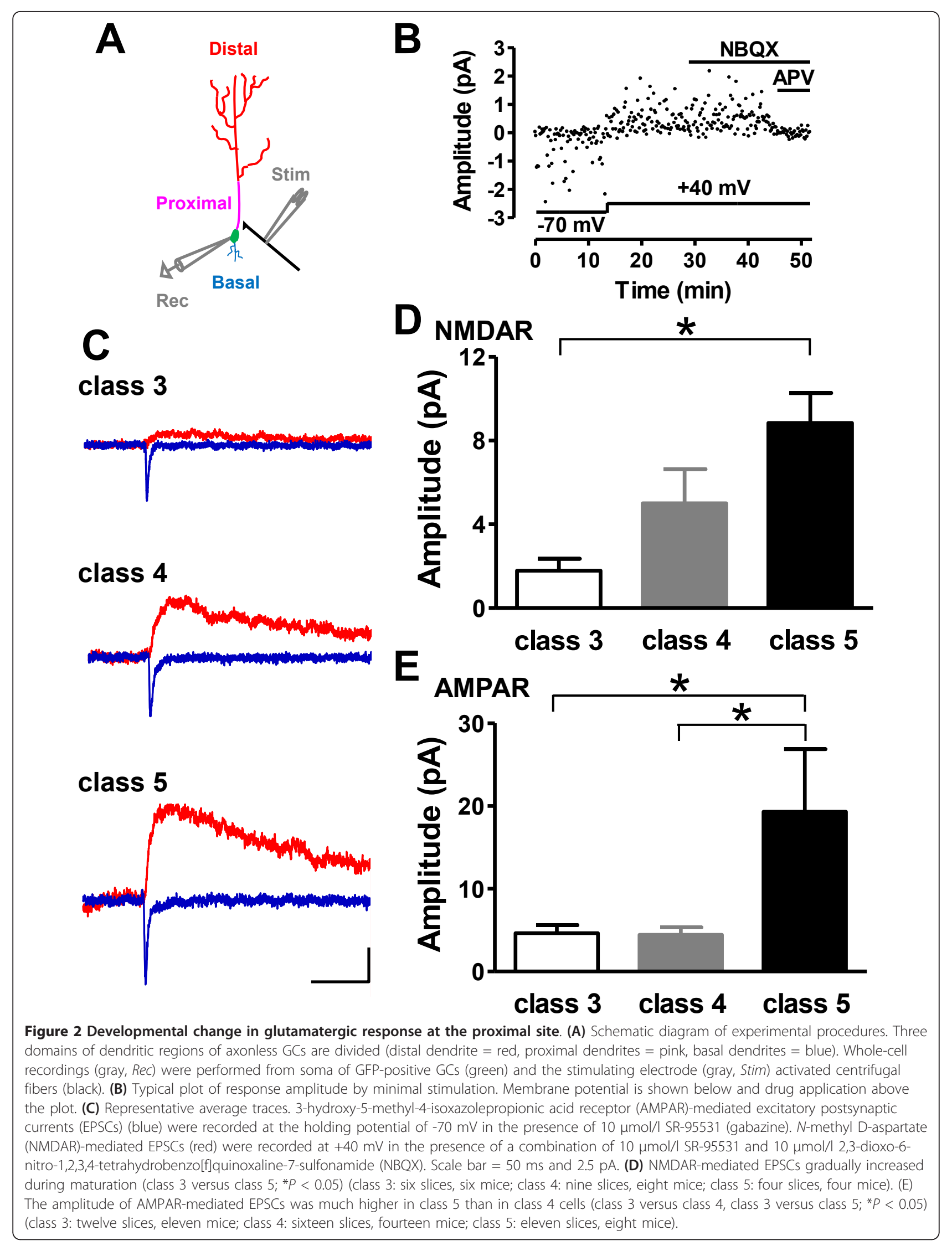


[18-20]. Whereas TC axon collaterals are superficially distributed in the internal plexiform layer, $\mathrm{MC}$ axon collaterals provide proximal glutamatergic inputs [20,21]. In addition, the somata and proximal domain of GC dendrites are the major targets of centrifugal fibers derived from several brain areas [22-24]. Interestingly, tetanic stimulation of centrifugal fibers can result in a long-lasting increase in excitatory synaptic transmission at the proximal synapses of GCs $[25,26]$. This ability to undergo synaptic plasticity is present in young rodent pups [25], and is only seen in adult-generated, developing interneurons in older animals [26]. As developing newborn GCs integrate into pre-existing OB circuits, they receive early excitatory proximal inputs that can profoundly influence their final stages of development, including the feed-forward inhibition they provide to their postsynaptic targets. However, how these early synaptic inputs on new neurons form and mature over time is still unknown.

In this study, we focused on the excitatory proximal inputs to newborn GCs. Pioneering studies on embryonal and postnatal development have shown that the first contacts to be formed are MC-GC dendrodendritic synapses at embryonic day (E)17. The formation of these first synaptic contacts is followed by the appearance of MC-GC axodendritic synapses at E18 [27,28]. Thus, key synapses important for the OB functioning are already present at birth, when olfaction is crucial for the survival of rodent pups. In contrast to embryonic synaptogenesis, we found that axodendritic proximal synapses were the first synaptic contacts formed on developing new GCs, shortly after the newcomer migrates radially into the bulb. Using electrophysiological and morphological approaches, we demonstrated that proximal synaptic inputs on newborn GCs are functionally developed and profoundly evolved over time much before the appearance of their output synapses. The overall developmental pattern of the proximal inputs on newborn GCs may be essential to shape the functional impact of the adult neurogenesis and, as a consequence, for proper circuit function.

\section{Results}

\section{Structural reorganization of the glutamatergic synapses} during GC maturation

Previous morphological studies have shown that adultborn GCs can be categorized into five distinct classes [29]. To characterize the early steps of synaptic integration, we focused on class 3 to class 5 neurons. We thus excluded migrating neurons (class 1 and 2) from the present analysis, as these cells do not exhibit direct synaptic activity (data not shown). We injected a green fluorescent protein (GFP)-encoding lentiviral vector into the rostral migratory stream (RMS) to label migrating neuroblasts [12,30]. At 3 days post-injection (dpi) of viruses, most GFP-positive cells were still navigating in the RMS, but a small proportion had already reached the bulb class 3 neurons (Figure 1A; see [30]). Their apical dendrites first reached the external plexiform layer a few days later (class 4). This step was followed by the formation of lateral branches with spines (class 5) (Figure 1A).

To examine early glutamatergic inputs contacting newborn GCs, we used pre-embedding immunolabeling for GFP combined with electron microscopy (EM). This ultrastructural analysis was performed in the deep portion of the GC layer, thus excluding TC axons located in the internal plexiform layer. At $7 \mathrm{dpi}$, EM analysis showed GFP-positive cells in the GC layer receiving asymmetric contacts from axon terminals. Serial sectioning revealed that some synapses at $7 \mathrm{dpi}$ had a simple shape with a compact and homogeneous post-synaptic density (PSD) (7 over 13 sections) (Figure 1B, single cell; Figure $1 C$ ), whereas other synaptic junctions exhibited discontinuities of the PSD (6 over 13 sections; not shown). Synapses impinging onto more advanced maturing cells $(21 \mathrm{dpi})$ and pre-existing GFP-negative cells exhibited more complex postsynaptic profiles, most notably, a doughnut-like shape with the PSD forming an almost complete ring around the central 'hole' (Figure 1B) (21 dpi cells: 5 over 13 sections; GFP-negative cells: 6 over 16 sections). Despite changes in the shape of the synaptic junctions, we did not observe any obvious differences in the ultrastructure of the presynaptic boutons contacting GC spines throughout the distinct maturation stages. All in all, these observations suggest that early proximal excitatory inputs on adult-generated GCs are formed within a few days of these cells arriving to the GC layer and that they then undergo a reorganization of PSDs (Figure 1D) during subsequent maturation stages.

\section{Functional characterization of early proximal glutamatergic inputs on new GCs}

To investigate the functional properties of developing synapses in the GC layer, we monitored electrophysiological events using whole-cell patch-clamp recordings (Figure 2A). We first analyzed the profiles for both inward $\mathrm{Na}^{+}$currents and input membrane resistance $\left(\mathrm{R}_{\text {in }}\right)$. Previous studies showed that inward $\mathrm{Na}^{+}$currents appeared mostly on class 5 newborn GCs; that is, one week after viral injection [8]. The presence of the apical dendrite was visualized both by GFP labeling and by loading cells with biocytin during patch-clamp recordings (Figure 1A). As expected, total dendritic length increased together with the increase in amplitude of the $\mathrm{Na}^{+}$current (see Additional file 1A). By contrast, an inverse correlation was found between the $\mathrm{Na}^{+}$current 
amplitude and $R_{\text {in }}$ (see Additional file $1 B$ ), known to decrease during neuronal maturation [8]. Therefore, the amplitude of the voltage-gated $\mathrm{Na}^{+}$current could be used as a reliable proxy of maturation stage (see Additional file $1 \mathrm{C}$ ). Rather than categorizing recorded cells by the number of dpi (see Additional file 1D), we classified recorded individual GFP-positive GCs according to the combination of three parameters: 1) maximum $\mathrm{Na}^{+}$ current amplitude, 2) dendrite length, and 3) $R_{\text {in }}$ values. Class 3 neurons, recorded at about $4 \mathrm{dpi}$, expressed a $\mathrm{Na}^{+}$current of $<150 \mathrm{pA}$, dendrite length $<100 \mu \mathrm{m}$ and $R_{\text {in }}$ values $>2.7 \mathrm{G} \Omega$ (see Additional file 1). Class 4 neurons, recorded at about $6 \mathrm{dpi}$, had a $\mathrm{Na}^{+}$current amplitude ranging from 200 to $800 \mathrm{pA}$, dendrite length of up to $280 \mu \mathrm{m}$ and $R_{\text {in }}$ values of between 2.3 and $5 \mathrm{G} \Omega$. Class 5 neurons, recorded at about $21 \mathrm{dpi}$, had a $\mathrm{Na}^{+}$ current amplitude $>800 \mathrm{pA}$, dendrite length of up to $310 \mu \mathrm{m}$ and $\mathrm{R}_{\text {in }}$ values $<2.5 \mathrm{G} \Omega$.

We then mapped connectivity for the recorded GCs using a minimal stimulation protocol delivered at proximal domains of GC dendrites. Previous studies suggested that excitatory glutamatergic inputs to the proximal dendrites of GCs originate from local collaterals of MC axons and centrifugal feedback projections from cortical regions [17]. However, these two inputs differ substantially in their location in the GC layer; centrifugal inputs remain deep in the GC layer $[16,17]$. Using this criterion, we focused our analysis on inputs showing the hallmarks of centrifugal feedback projections $[17,26]$, bearing in mind that patch recordings are performed from the cell body whereas the synapses on the EM analysis originate from the dendritic spines some distance away on proximal dendrites. Starting with a low-intensity stimulation that did not evoke any excitatory postsynaptic currents (EPSCs), we then increased the stimulus strength gradually until a fast EPSC appeared. Only when a stimulating electrode was placed into the GC layer (Figure 2A) near the soma of the class 3 neurons did we observe EPSCs in an "all or nothing" manner (Figure 2B and Additional file 2). In our previous report [26], using a similar position for the stimulating electrode we observed EPSCs similar to those evoked by the axodendritic inputs in the proximal domain of the apical dendrite (Figure 2A). Stimulation near this recruitment threshold often failed to induce an EPSC. Slightly increasing the stimulation intensity beyond that threshold prevented the occurrence of failures, without affecting the amplitude of successful responses (see Additional file 2). In all cases, further small increments in stimulus intensity did not affect EPSC amplitude.

We characterized the development of synaptic inputs for the three classes of newly-formed neurons by using the voltage-clamp technique to measure isolated AMPAR-mediated EPSCs at a holding potential of $-70 \mathrm{mV}$. After EPSCs were recorded at $+40 \mathrm{mV}$ with the same stimulus strength, we applied the AMPAR antagonist 2,3-dioxo-6-nitro-1,2,3,4-tetrahydrobenzo[f] quinoxaline-7-sulfonamide (NBQX) at $10 \mu \mathrm{mol} / \mathrm{l}$. Finally, we confirmed, using the NMDAR antagonist D,L-2-amino5-phosphonopentanoic acid (D,L-APV) at $100 \mu \mathrm{mol} / \mathrm{l}$, that EPSCs were mediated by NMDAR. Gabazine (SR95531) at $10 \mu \mathrm{mol} / \mathrm{l}$ was used to block $\mathrm{GABA}_{\mathrm{A}}$ receptor-mediated events and was present throughout all experiments. Minimal stimulation evoked both AMPARmediated and NMDAR-mediated EPSCs in newborn GCs in a success or failure manner (Figure 2B, C). After we subtracted mean failure responses from all responses (that is, success and failure) to prevent the obscuration by the stimulus artifact, we compared AMPAR-mediated and NMDAR-mediated EPSC amplitude among classes. NMDAR-mediated current amplitude gradually increased with more advanced maturation (class 3: $1.8 \pm$ $0.6 \mathrm{pA}$; class 4: $5.0 \pm 1.6 \mathrm{pA}$; class 5: $8.8 \pm 1.4 \mathrm{pA}$ ) (Figure 2D). By contrast, AMPAR-mediated EPSC amplitude did not differ between class 3 and class 4 GCs (class 3: $4.6 \pm 1.0 \mathrm{pA}$; class $4: 4.4 \pm 0.9 \mathrm{pA}$ ), but was significantly increased in class 5 neurons $(19.3 \pm 7.6 \mathrm{pA} ; p<0.05)$ (Figure 2E). These findings show that stimulation of $\mathrm{OB}$ slices, when delivered at minimal intensity, is a useful approach to study the maturation of a single presynaptic terminal contacting a maturing adult-generated GC.

To exclude the possibility that the abrupt increase in AMPAR-mediated EPSC amplitude at class 5 might reflect the transition from regimens in which $\mathrm{Na}^{+}$current is adequately clamped (class 3 and 4 ) to a regimen in which potentially it could not be clamped so well (class 5), we compared the amplitude of AMPARmediated outward EPSCs at the depolarized membrane potential. When these currents were derived from the subtraction of NMDAR-mediated components from EPSCs without NBQX, we obtained similar results (see Additional file 3). Taken together, these results suggest that NMDAR and AMPAR might have distinct roles during the maturation processes of adult-born GCs.

\section{Functional maturation of NMDAR- and AMPAR-mediated EPSCs}

The kinetics of postsynaptic currents, including NMDARmediated and AMPAR-mediated events at various synapses, differ at different stages of neuronal maturation [31]. During the early stages of development, the predominant form of synaptic current is known to be mediated by NMDAR, which then declines rapidly with age and/or neuronal activity [32]. Thus, we examined in detail the kinetics of evoked EPSCs in developing GCs. The 10-90\% rise times of NMDAR-mediated EPSCs gradually decreased during maturation (class 3: $23.0 \pm 3.3 \mathrm{~ms}$; class 4: $17.0 \pm 3.0 \mathrm{~ms}$; class 5: $8.2 \pm 1.2 \mathrm{~ms}$ ) (Figure 3A). The decay time constant of NMDAR-mediated EPSCs, which 


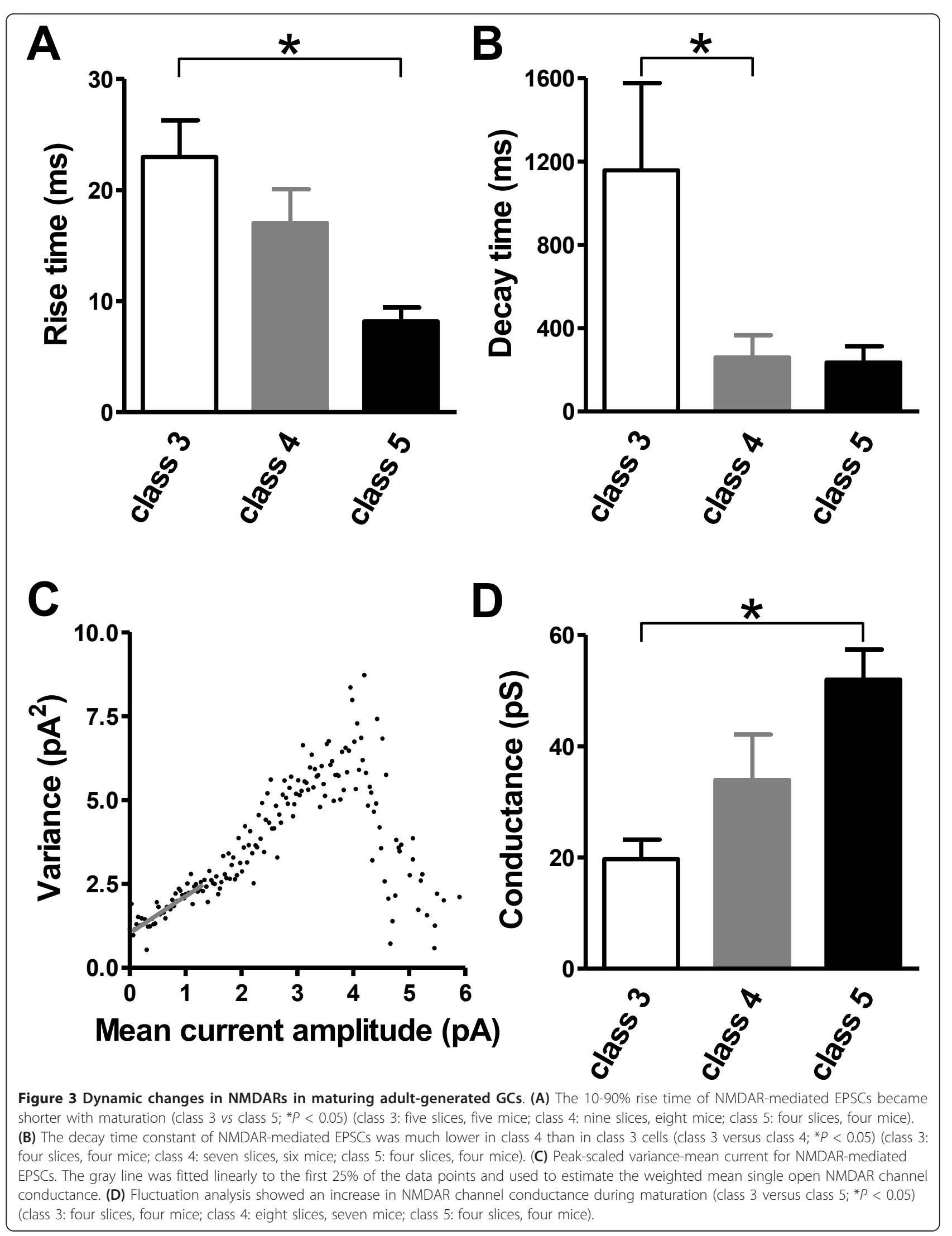


was characterized by a double exponential function, also significantly decreased over time (class 3: $1158 \pm 419 \mathrm{~ms}$; class 4: $260 \pm 107 \mathrm{~ms}$; class 5: $235 \pm 77 \mathrm{~ms}$ ) (Figure 3B). In line with these results, developmental switches in NMDAR subunits are known to shorten NMDARmediated EPSC durations [33].

The conductance of ionotropic glutamate receptors depends on subunit composition [34]. We therefore used non-stationary fluctuation analysis to estimate single-channel conductance $[35,36]$. The relationship between the variance and mean amplitude of NMDARmediated current was found to be skewed (Figure 3C). We fitted the initial slope to estimate the mean singlechannel current underlying NMDAR-mediated EPSCs, and then calculated the single channel conductance. Results showed a gradual increase in NMDAR singlechannel conductance over time (class 3: $19.7 \pm 3.5 \mathrm{pS}$; class 4: $33.9 \pm 8.2 \mathrm{pS}$; class 5: $52.0 \pm 5.4 \mathrm{pS}$ ) (Figure 3D).

By contrast, the properties of AMPAR-mediated EPSCs remained unchanged over the same time window (Figure 4). AMPAR-mediated EPSCs showed a similar $10-90 \%$ rise time for the different stages of maturation (class 3: $0.7 \pm 0.1 \mathrm{~ms}$; class 4: $0.8 \pm 0.1 \mathrm{~ms}$; class 5: $0.9 \pm 0.1 \mathrm{~ms}$ ) (Figure 4A) and similar decay time constants (class 3: $2.8 \pm 0.2 \mathrm{~ms}$; class 4: $2.7 \pm 0.2 \mathrm{~ms}$; class 5: $2.7 \pm 0.3 \mathrm{~ms}$ ) (Figure 4B). Non-stationary fluctuation analysis showed a parabolic relationship between the variance and the mean EPSC amplitude (Figure 4C). The mean single-channel current was thus derived from the parabolic function. Once again, single-channel conductance did not significantly differ among maturation stages (class 3: $23.9 \pm 3.0 \mathrm{pS}$; class 4: $19.4 \pm 2.8 \mathrm{pS}$; class 5: $25.1 \pm 3.8 \mathrm{pS}$ ) (Figure 4D). These findings suggest that NMDARs, but not AMPARs, undergo a functional rearrangement during development, including, for example, a change in subunit composition.

\section{Mechanism of transmitter release at newly-formed synapses}

Functional changes in proximal synapses on new GCs may be simultaneously regulated at postsynaptic and presynaptic sites. We examined presynaptic features using a paired-pulse protocol (interstimulus interval $50 \mathrm{~ms}$ ) (Figure 5A) previously used to measure the efficacy of neurotransmitter release from the presynaptic terminal [37]. The ratio of the success rate of the second response to the success rate of the first response was $>1$ and remained constant for all neuronal classes (class 3: $1.41 \pm 0.10$; class $4: 1.36 \pm 0.13$; class $5: 1.37 \pm 0.04$ ) (Figure 5B). We also compared the ratio of the average amplitude of AMPAR-mediated EPSCs (all successes and failures) for the first stimulus to that of the second for developing GCs (Figure 5C). The degree of facilitation in response to paired-pulse stimuli was similar for all classes (class 3: $1.35 \pm 0.07$; class 4: $1.39 \pm 0.12$; class 5: $1.42 \pm 0.09$ ) (Figure 5D), which suggested that maturation of new GCs was not linked to a change in the probability of glutamate release. Thus, the rapid increase in the NMDAR/AMPAR ratio over time results primarily from postsynaptic changes.

The combination of minimal and paired-pulse stimulation techniques allowed analysis of the evoked EPSCs for which transmitter release was detected in response to both the first and second stimulation (Figure 6A). We measured mean amplitudes for the first and second responses, considered as the 'potency' of each pulse. Only class $3 \mathrm{GCs}$ had similar potency values for both responses. If one proximal synapse has only one functional release site, zero or one quantum can be released. Thus, if both the first and second pulses generated successful responses, releasing one quantum, there would be no difference in the size of these responses; that is, the potency ratio (second pulse to first pulse) would be 1. However, if multiple release sites contribute to the synaptic response, the second pulse may induce the simultaneous release of multiple transmitter quanta, generating a larger synaptic response for the second pulse than for the first. Figure $6 \mathrm{~B}$ shows the potency ratio plotted as a function of the ratio of the mean amplitude of evoked EPSCs (successes and failures). Most data from class 5 cells, but not from class 3 or 4 cells, could not be expressed as a horizontal line (potency ratio $=1$ ). When a linear regression line was fitted to all the data, the slope increased significantly during maturation (class 3: $0.15 \pm 0.31$; class 4: $0.21 \pm$ 0.15; class 5: $0.94 \pm 0.32$ ). The slope was significantly non-zero only for class 5 GCs (class 3: $P=0.66$; class 4: $P=0.20$; class $5: P=0.03)$. Thus, these data suggest that more than one single release site accounts for the synaptic responses recorded in class 5 cells. Changes in potency could be simulated by success rates of the experimental data using a simple Poisson release model (Figure 6C). This model assumes activation of multiple functional release sites with low release probability [38-40]. The predicted potency ratio was significantly greater than the measured ratio for class $3 \mathrm{GCs}$ only $(p=0.01)$ and this difference between predicted and measured potency ratios disappeared with maturation (class 4: $P=0.43$; class $5: P=0.64$ ). These results suggest that the number of functional release sites at proximal synapses may increase from class 3 to class 5 .

\section{Properties of proximal synapses on mature GCs}

We also examined the electrophysiological properties of class 5 cells at later time points after viral injection. At about $14 \mathrm{dpi}$, newborn class $5 \mathrm{GCs}$ exhibit long-term potentiation (LTP) at proximal glutamatergic synapses, but this plasticity disappears over time [26]. Thus, the 


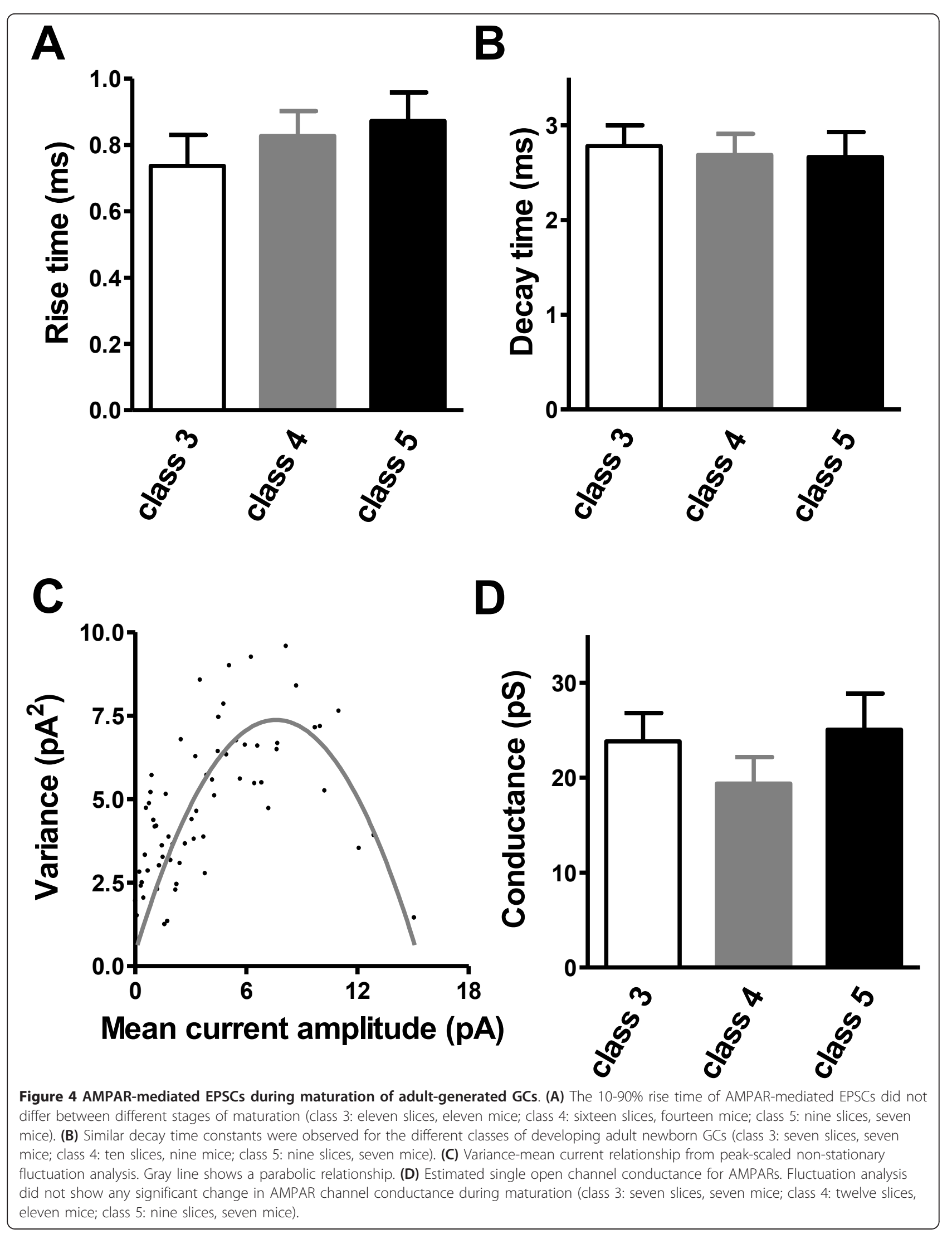




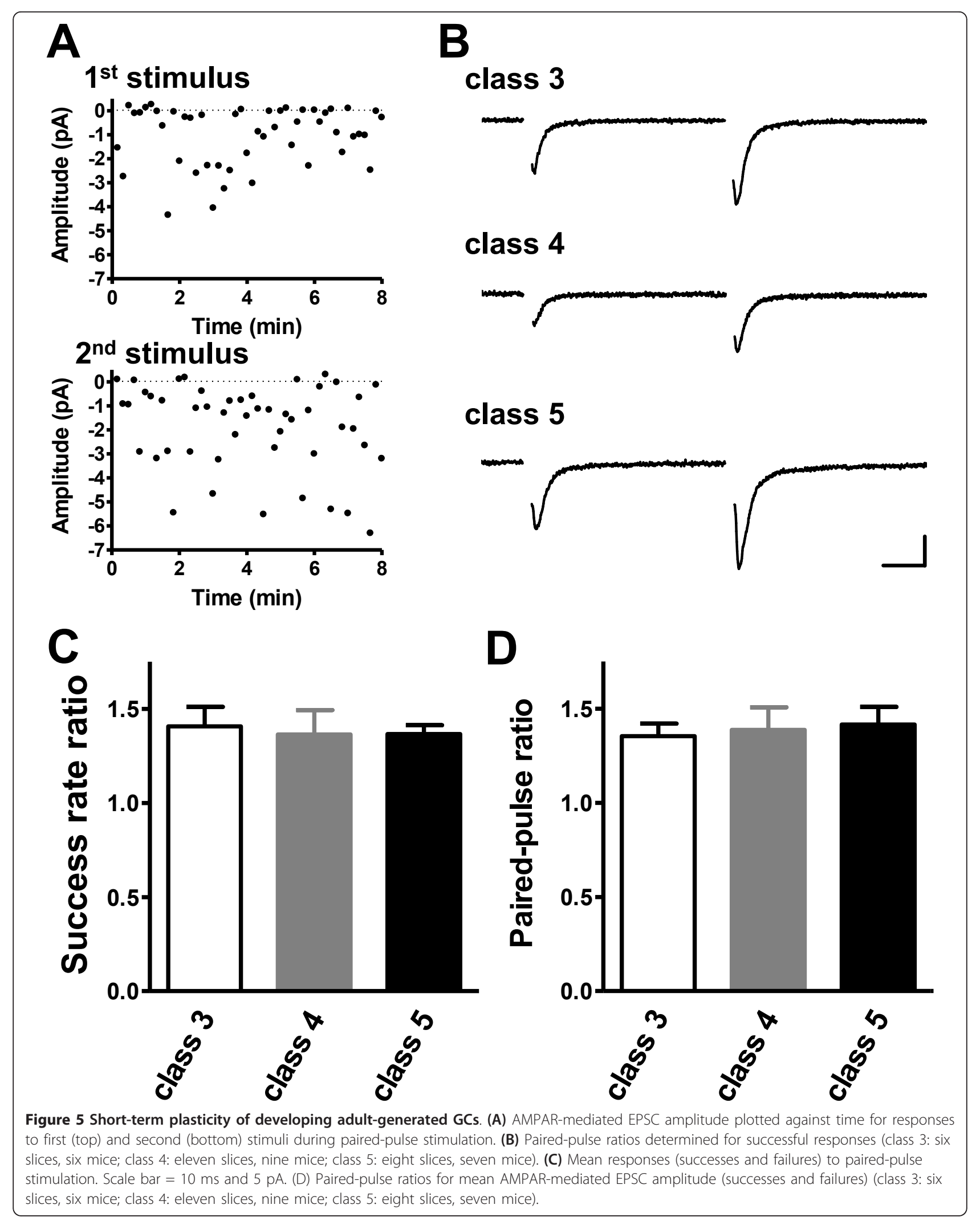




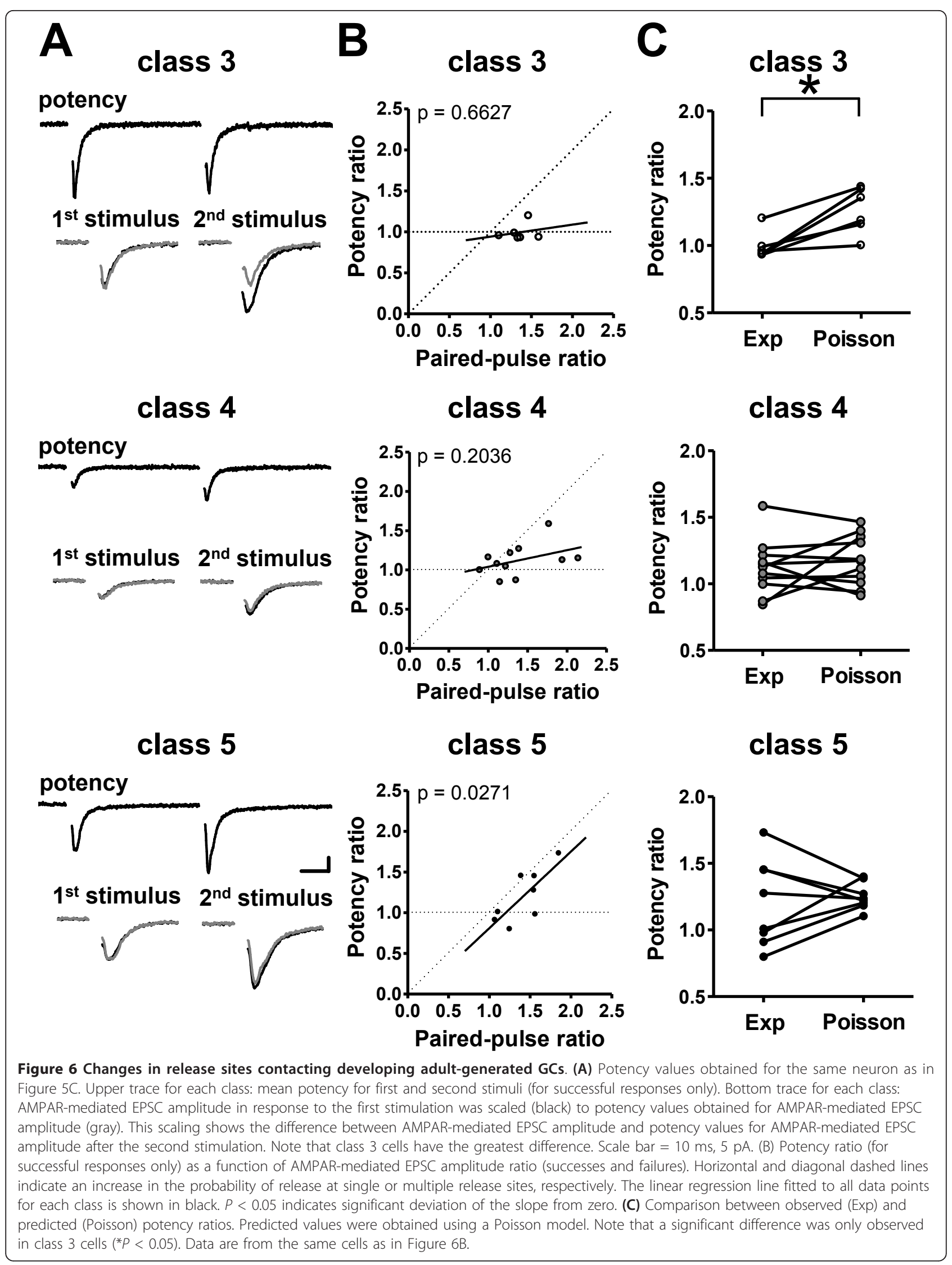


properties of the input synapses on fully mature GCs may differ from those of synapses on class 5 cells. To examine this possibility, two consecutive stimuli of minimal intensity were delivered to evoke neurotransmitter release from presynaptic terminals contacting mature non-GFP-labeled GCs (Figure 7A). The success rate of the second response exceeded that of the first (a ratio of $1.45 \pm 0.17$ ) (Figure 7B). Paired-pulse stimulation also resulted in the facilitation of the mean AMPARmediated current amplitude in pre-existing mature GCs (a ratio of $1.33 \pm 0.15$ ) (Figure 7A). Neither the success rate ratio nor the paired-pulse ratio differed between developing and mature GCs. The predicted potency ratio was significantly greater than the observed ratio in mature GCs (Figure 7C). Consistent with this result, the linear regression line that fitted data obtained from mature GCs was almost parallel to the horizontal line (slope $0.09 \pm 0.15$ ) (Figure 7C). The predicted potency ratio by a simple Poisson release model was also significantly greater than the measured ratio for mature GCs $(P<0.03)$. Similar to the findings for class 3 cells, these results indicate that mature GCs receive proximal synapses characterized by a single functional release site.

Although the amplitudes of AMPAR-mediated and NMDAR-mediated EPSCs recorded from mature GCs were significantly higher than those from class $3 \mathrm{GCs}$ (AMPAR-mediated events $26.7 \pm 8.2 \mathrm{pA}$; NMDARmediated events $11.8 \pm 5.1 \mathrm{pA}$ ), the NMDAR/AMPAR ratios for mature and class 3 GCs were indistinguishable (Figure 7D). This ratio was maximal for class 4 and class 5 neurons (class 3: $0.47 \pm 0.11$; class 4: $1.30 \pm 0.17$; class 5: $0.88 \pm 0.28$; mature: $0.57 \pm 0.28$ ). These findings suggest that AMPARs are functionally dominant at proximal synapses in both class 3 neurons and mature GCs.

\section{Discussion}

This study shows that early functional glutamatergic inputs contact the developing adult-born GCs at proximal sites, well before glutamatergic synapses appear at the distal domain, consistent with previous studies $[11,13,32]$. Our EM analysis of the GC layer, together with other physiological studies $[17,25,26]$, identifies these proximal inputs as axodendritic synapses originating from a variety of brain regions. These include projections from pyramidal cells in secondary olfactory cortical areas, frontal cortex and hippocampal structures $[22,41,42]$. Our approach demonstrates, for the first time, a functional maturation pattern of the synaptic elements at these glutamatergic inputs (Figure 8A). The NMDAR/AMPAR ratio reached maximum in class 4 cells, with lower values observed in more immature or mature GCs. This time window precisely corresponds to the critical period during which the survival of newborn
GCs is highly sensitive to sensory experience [43] and needs functional NMDARs [44]. Similarly, multiple functional release sites were detected only in class 4 and 5 cells during the same time window. At the end of the critical period, the glutamatergic terminals revert slowly to bearing only a single release site. This study emphasizes the precise orchestration for the maturation of presynaptic and postsynaptic elements at the synaptic proximal inputs onto adult-born GCs, in contrast to the situation for neonatal GCs, where dendrodendritic synapses first appear before axodendritic synapses $[27,28]$.

\section{Formation of the first glutamatergic contacts}

Class 1 and 2 cells are migratory neurons [29], which express AMPAR before reaching their final position in the bulb $[8,45]$. AMPAR-mediated current recorded from these migrating cells showed an almost linear current-voltage relationship, indicative of $\mathrm{Ca}^{2+}$-impermeable AMPARs [8]. By contrast, AMPAR-mediated currents at the proximal synapses of class 3 cells showed inward rectification (see Additional file 4) indicative of the presence of $\mathrm{Ca}^{2+}$-permeable AMPAR channels, as it has been recently demonstrated using flash photolysis of caged glutamate [46]. Supporting this assumption is the large single channel conductance for AMPAR estimated from our non-stationary noise analysis (Figure 4D), as previously reported [47]. Intracellular $\mathrm{Ca}^{2+}$ is thought to play an important role in regulating the migration and maturation of newborn neurons [45,48]. Further experiments will determine whether this $\mathrm{Ca}^{2+}$ permeability mediates a stop signal that halts the radial migration of new GCs, as demonstrated for migrating neurons of the embryonic cortex [49].

Class 3 GCs that have just reached the OB show limited dendritic arborization $(<100 \mu \mathrm{m})$ and a virtual absence of spines; however, we detected early functional glutamatergic inputs at this time point (Figure 2). Meanwhile, newborn neurons in the hippocampus receive their first glutamatergic synapses about two weeks after developing in the GC layer [50]. Further studies should investigate whether the difference in the onset of glutamatergic inputs might support differences in new neuron turnover between the $\mathrm{OB}$ and hippocampus, as previously reported [51].

We found that a single axon terminal formed synapses onto the dendrites of both GFP-positive and GFPnegative GCs (see Additional file 5). This suggests that immature and mature synapses share the same presynaptic input, assuming that GFP-negative cells represent mature pre-existing GCs. Notably, the distance between synapses in immature and pre-existing GC dendrites can be as small as $<1 \mu \mathrm{m}$ (see Additional file 5). Such proximity suggests that new GCs may integrate into the 


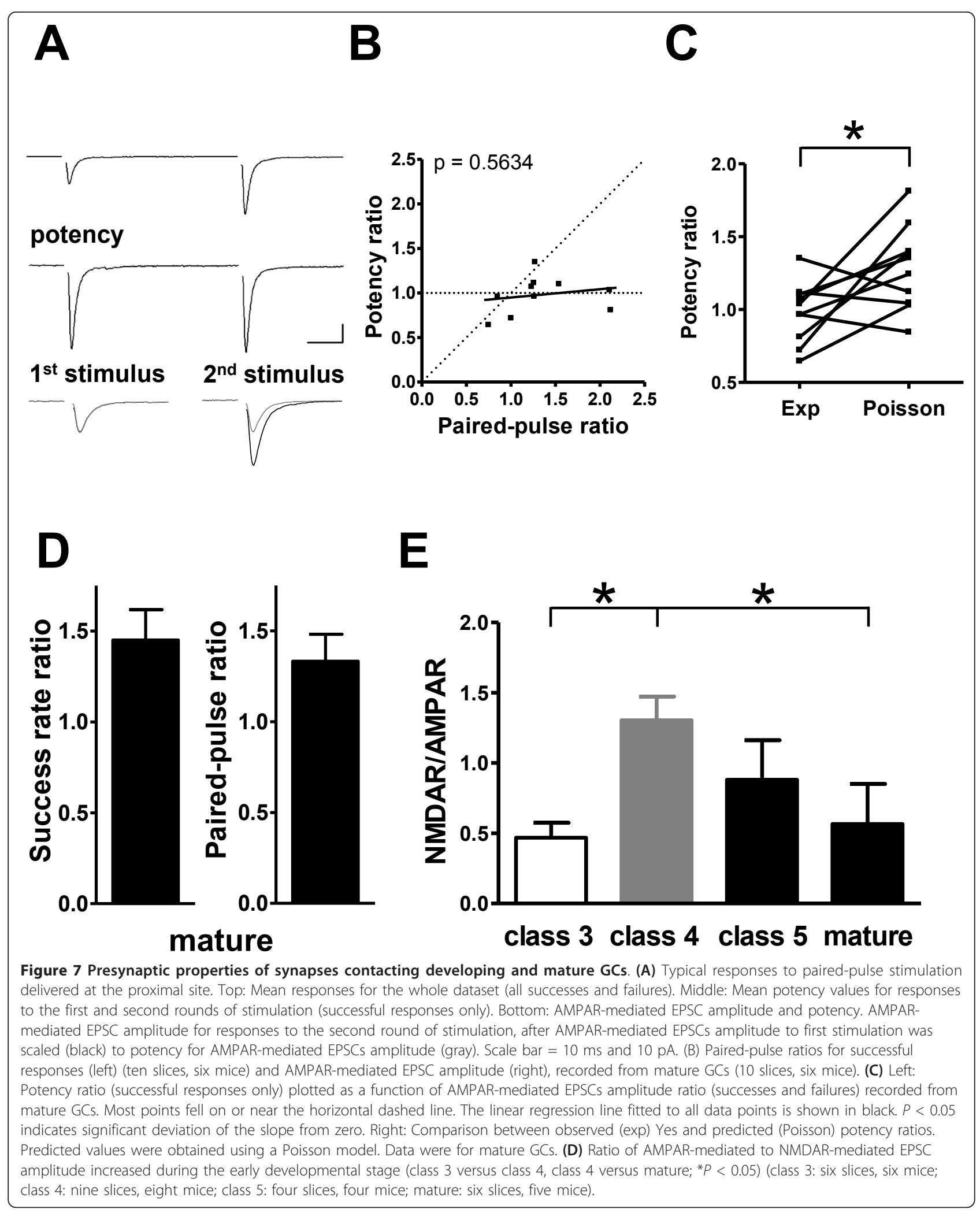




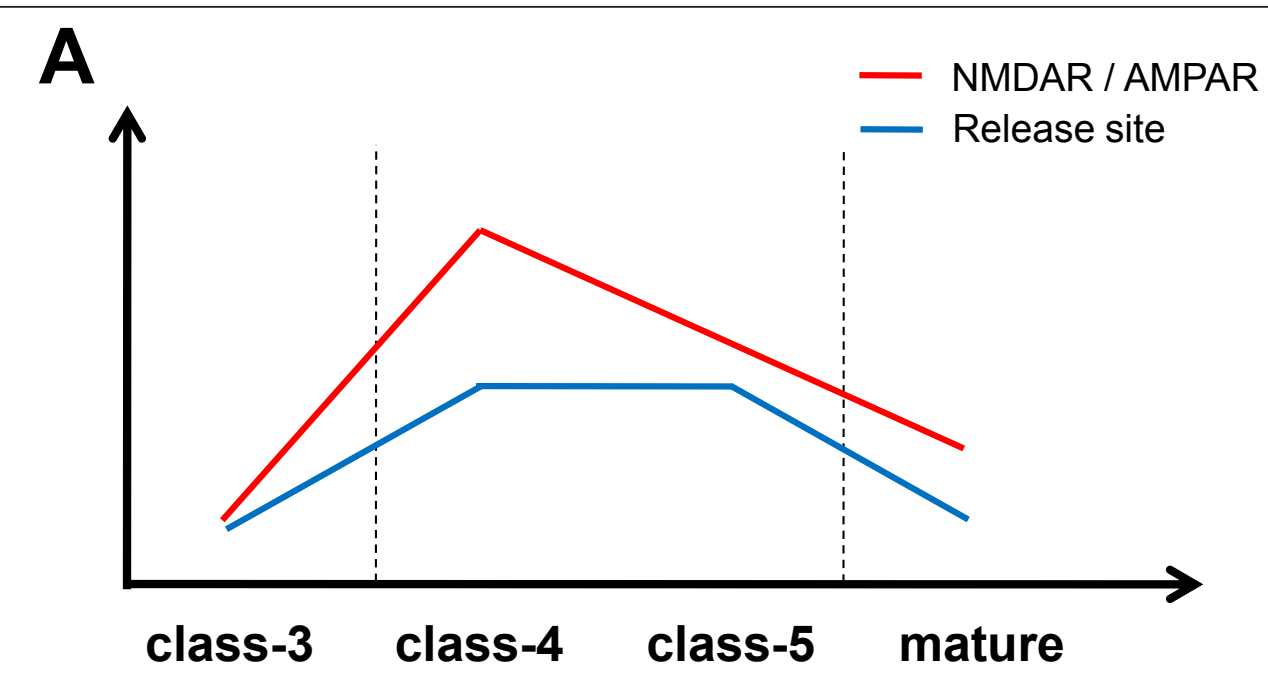

B
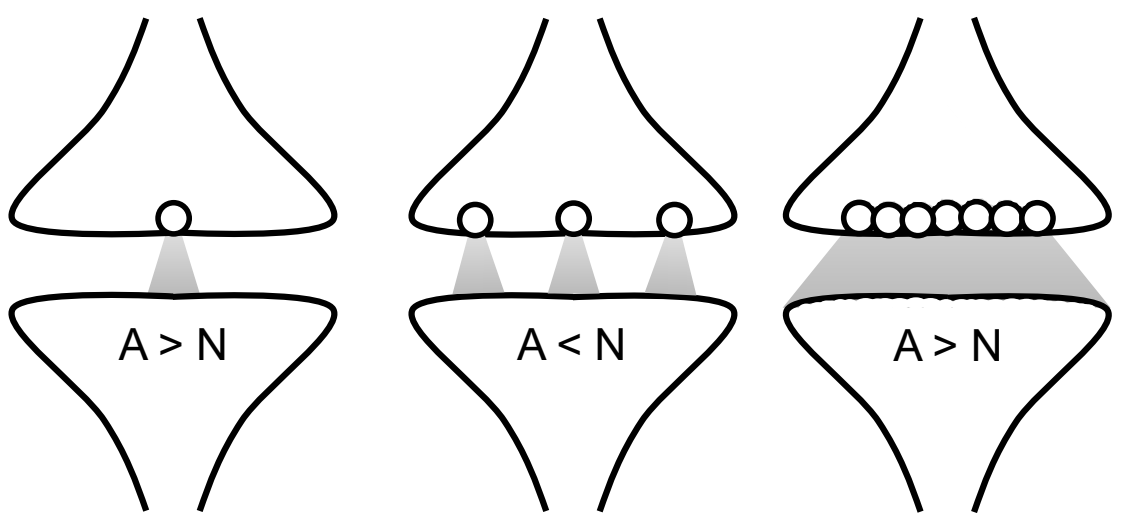

\section{class -3 class -4 class -5 mature}
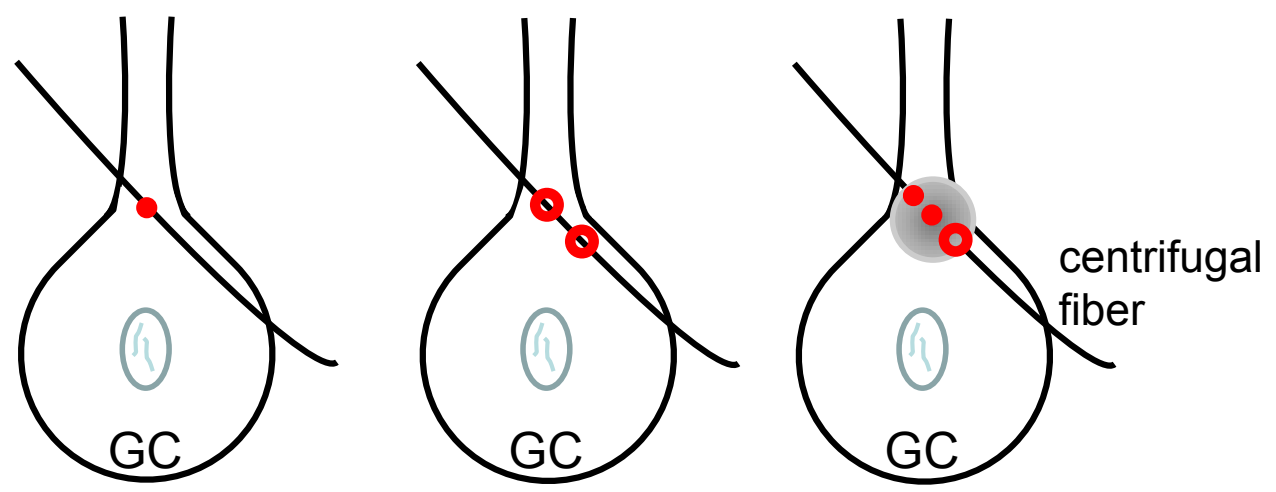

Figure 8 Schematic diagram of an axodendritic synapse for each class of GC. (A) Time-course analysis of two elements during the maturation of the first glutamatergic contact onto newborn GCs. The NMDAR/AMPAR ratios are shown in red. Functional release sites (blue) are indicated as either single or multiple. Both class 4 and class 5 neurons showed a high NMDAR/AMPAR ratio with multiple release sites.

(B) Developmental changes in a single axodendritic synapse. Top: Transmitter vesicular events (circle) per action potential gradually changed from single to multiple events. Each event occurred independently, but seemed to become integrated together in mature GCs (gray). Bottom: Differences observed in the number of axodendritic synapses. During maturation, the number of synapses (red circles) impinging onto newborn GCs increased in parallel with the appearance of perforated synapse (red doughnut-like shape). At the later stages of maturation, perforated synapses then divided, with a spillover of transmitter occurring at adjacent synapses (gray). 
mature circuit using pre-existing terminals, as previously described for new neurons of the adult dentate gyrus [52]. Upon arrival of a new GC, glutamate release from the pre-existing terminals may trigger the extension of dendritic filopodia, resulting in the formation of postsynaptic specializations. At the same time, directed recruitment of mobile vesicles to nascent active zones in pre-existing terminals [53] may lead to the formation of additional presynaptic release sites (Figure 8B, bottom). One potential benefit of such a coordinated mechanism would be the ability to rapidly initiate the formation of new synapses.

\section{Maturation of glutamatergic synapses at the postsynaptic site}

When a presynaptic fiber contacts the proximal dendrites of class 3 neurons, mobile transport packets, containing presynaptic and postsynaptic proteins, are immediately recruited for synaptic maturation [53]. We observed that the amplitude of EPSCs mediated only by NMDAR was higher in class 3 than in class 4 cells. Furthermore, NMDARs may also play an active role in keeping immature synapses free from AMPARs until an appropriate trigger signals the recruitment of this receptor, as described in developing circuits [54]. Thus, the incorporation of NMDARs may precede the insertion of AMPARs during the early maturation stages in adult newborn GCs.

We also found a shorter duration of NMDARmediated currents in class 4 neurons than in class 3 neurons. Increasing evidence suggests an acceleration of NMDAR-mediated events during neuronal maturation, reflecting a switch in subunit composition [55]. NMDARs consist of two obligate NR1 subunits and two NR2A-D or NR3A-B subunits, the recruitment of which depends on spatial and developmental signals [56]. Our findings indicate that NMDAR channel conductance increased from low to high conductance during the maturation process, possibly because the NMDARmediated currents recorded in class 3 cells were presumably mediated by NR2D-containing receptors, known to support low conductance states [57]. Reconstructed systems have shown that NR2D-containing receptors mediate currents with a long decay-time constant [58], consistent with the prolonged decay-time constant observed in class 3 cells. Additionally, morphological analyses have shown that the NR2 D subunit is mainly located at extrasynaptic sites [59]. The slow rise time of NMDAR-mediated currents recorded from the centrifugal fibers of class 3 cells could result from the activation of extrasynaptic NR2D-containing receptors. Then, during maturation of newborn cells from class 3 to class 4, high-conductance NMDARs may be recruited from extrasynaptic to synaptic sites. This scenario would be consistent with the shortened rise time of NMDAR- mediated currents observed at the later maturation stages; however, pharmacological experiments should be conducted to directly test this possibility.

During development, glutamatergic synaptic currents undergo a characteristic pattern of maturation involving changes in the kinetics of NMDAR-mediated currents. The formation of 'silent' synapses, which display only NMDAR-mediated currents and which are later made functional through recruitment of AMPARs, is also a possibility. These changes in glutamatergic synapses during maturation have implications for the early development of neural networks [60] and for the mechanisms underlying the LTP of synaptic efficacy [61]. In our study, we detected the highest NMDAR/AMPAR ratio in class 4 cells, even though axodendritic synapses are not 'silent' at the stage of class 3. This high NMDAR/AMPAR ratio declined with neuronal age as a result of AMPAR recruitment. This observation suggests that the development of axodendritic synapses after the class 4 stage (that is, from $6 \mathrm{dpi}$ ) somewhat recapitulates the mechanism of maturation described during brain development.

\section{Changes in synapse ultrastructure on developing GCs}

Our study found changes in functional release sites during the maturation process. Minimal stimulation experiments revealed the presence of a single functional release site in class $3 \mathrm{GCs}$ and multiple functional release sites in both class 4 and class 5 GCs. Previous studies have shown that multiple vesicles might be released at each synaptic contact for each action potential fired $[62,63]$. These changes could reflect a maturation of individual synapses, involving developmental switching from single to multiple release sites (Figure $8 \mathrm{~B}$, top) [62,63]. Indeed, previous ultrastructural analyses have demonstrated that developing (class 3) neurons establish immature synapses characterized by small cluster of vesicles (that is, a group of $>4$ vesicles) and faint membrane specializations [11], whereas mature synapses contain large cluster of vesicles and substantial asymmetric membrane thickening [11] (and this study).

Each neurotransmitter release site in the mature brain functions in a binary mode, releasing one or zero quantum of neurotransmitter for each action potential $[38,64]$. Therefore, many excitatory synapses in the mammalian brain can release a maximum of the contents of one vesicle [65]. Alternatively, the changes described here may reflect changes in the number of synaptic appositions contacting a given GC (Figure $8 \mathrm{~B}$, bottom). A single synapse may first develop into a more complex contact (involving the presence of perforations) and then split into two synapses, still connected to the same single axon. Interestingly, LTP has been reported to initiate the perforation of spines, leading to the appearance of multiple spine boutons [66]. Because LTP has been observed 
at the proximal synapses of GCs [25,26], it is possible that the changes in the number of synaptic contacts we found might reflect some form of synaptic plasticity.

At later stages of maturation, we found that GCs revert to a single functional release site. The paired-pulse ratio was smaller after supraminimal stimulation than after minimal stimulation in mature, but not in class 5 GCs ([26]) (Figure 7B). This could arise through presynaptic events, such as successful release at most release sites triggered by the first supraminimal pulse, or through postsynaptic events, such as saturation of receptors after multivesicular release [67]. Two possible models may thus be considered for the axodendritic synapse of mature GCs: individual boutons displaying multiple dense release sites (Figure 8B, top) or synaptic connections with multiple release sites in close proximity (Figure 8B, bottom). In both cases, multivesicular events occur in synchrony at the axodendritic synapse of more mature GCs.

\section{Conclusion}

In this study we found that, within a few days after having reached the $O B$, the first glutamatergic synapses underwent a dynamic developmental process. This proximal excitatory input is subjected to both physiological and morphological modifications before reciprocal dendrodendritic synapses start to operate at distal sites. Our results provide a conceptual framework for understanding mechanisms underlying the precise control of neural wiring through presynaptic and postsynaptic events during adult neurogenesis. It is remarkable that both basic physiological properties (this study) and the synaptic plasticity [26] were found to be continuously changing over time, even when the ultrastructure of newly-formed synapses became similar to that of mature counterparts. This finding contrasts with the observation that GCs in the adult dentate gyrus continue to change physiologically and morphologically after the formation of their first glutamatergic synapses $[50,68,69]$. We indicate here that the influence of adult $\mathrm{OB}$ neurogenesis may be gradually tuned by early glutamatergic synaptic transmission, depending on the activity of cortical structures downstream from the OB. Elucidating the origin of the glutamatergic centrifugal fibers impinging so early onto newborn GCs, and the molecular mechanisms that shape the integration of new neurons, has important implications both for understanding how $\mathrm{OB}$ circuits are refined by experience and for the successful use of stem cell-based replacement therapies in brain repair.

\section{Methods}

\section{Mice}

C57BL/6J male mice about eight weeks old (Janvier, France) were used for all experiments. All procedures were carried out in accordance with the EU Charter of
Fundamental Rights (2000/C 364/01) and the European Communities Council Directive of 24 November 1986 (86/609/EEC), and were reviewed and approved by our institutional animal welfare committee.

\section{Lentiviral vectors}

For cytosolic GFP labeling, a custom-built lentivirus containing the GFP gene under the control of the PGK promoter was used to transduce adult-born neurons as previously described [12]. Viruses $\left(2.2 \times 10^{10}\right.$ transducing units $(\mathrm{TU}) / \mathrm{ml}$ ) were stored at $-80^{\circ} \mathrm{C}$. Immediately before injection, the lentiviral vectors were diluted in phosphate-buffered saline (PBS) to a final concentration of $15 \mathrm{ng}$ of $\mathrm{p} 24$ protein per microliter.

\section{Stereotaxic surgery}

For stereotaxic injections of lentiviral vectors, adult mice about six weeks old were anesthetized with a mixture of ketamine (Imalgene ${ }^{\circledR}$, Merial, Lyon, France) $(1.5 \%$ in PBS) and xylazine $\left(\right.$ Rompun ${ }^{\circledR}$, Bayer Health Care, Puteaux France) (0.05\%; $250 \mu \mathrm{l}$ per mouse). Mice were mounted in a Kopf stereotaxic apparatus, and small craniotomies were created above the injection sites. Virus was injected into the rostral migratory stream (RMS) at the following co-ordinates in each hemisphere: anteroposterior $+3.3 \mathrm{~mm}$ from bregma; mediolateral $\pm 0.82 \mathrm{~mm}$ from bregma; and dorsoventral $-2.85 \mathrm{~mm}$ from pial surface. Injected mice were housed individually until used for electrophysiological experiments. Injections of the viral vector into the RMS specifically labeled adult-born migrating neuroblasts, with $\mathrm{OB}$ slices showing GFP expression in newborn interneurons only. We did not detect any diffusion from the injection site resulting in transduction of the resident OB cell population during the course of these experiments. This approach has been successfully used previously to characterize the morphological maturation of adult-born periglomerular cells [10].

\section{Slice preparation}

Mice were deeply anesthetized with isoflurane (Mundipharma, Issy-les-Moulineaux, France) and then rapidly decapitated. Horizontal slices from the OB and frontal cortices were obtained after decapitation and brain removal. After cutting, slices $(300 \mu \mathrm{m})$ were placed in oxygenated artificial cerebrospinal fluid (ACSF) at $35^{\circ} \mathrm{C}$ for $30 \mathrm{~min}$. Slices were then kept in bubbled ACSF at room temperature. ACSF contained $124 \mathrm{mmol} / \mathrm{l} \mathrm{NaCl}, 3 \mathrm{mmol} / \mathrm{l}$ $\mathrm{KCl}, 1.3 \mathrm{mmol} / \mathrm{l} \mathrm{MgSO}$, $26 \mathrm{mmol} / \mathrm{l} \mathrm{NaHCO} 3,1.25 \mathrm{mmol} /$ $1 \mathrm{NaHPO}_{4}, 20 \mathrm{mmol} / \mathrm{l}$ glucose and $2 \mathrm{mmol} / \mathrm{l} \mathrm{CaCl}$ (all chemicals from Sigma-Aldrich, Saint-Quentin, France).

\section{Whole-cell patch-clamp recordings}

Individual slices were placed in a submerged recording chamber and were continuously perfused with ACSF 
$(1.5 \mathrm{ml} / \mathrm{min})$ at room temperature. Whole-cell voltageclamp recordings from GCs in the GC layer were obtained using a $\times 40$ water-immersion objective, a halogen light source, differential interference contrast filters (all Olympus, Rungis, France), a charge-coupled device (CCD) camera (C7500; Hamamatsu, Japan) and an amplifier (EPC9/2; Heka Instrument, Port Washington, USA). Patch electrodes (6-10 M $\Omega$ ) were filled with an internal solution $(126 \mathrm{mmol} / \mathrm{l} \mathrm{Cs}$ gluconate, $6 \mathrm{mmol} / \mathrm{l}$ CsCl, $2 \mathrm{mmol} / \mathrm{l} \mathrm{NaCl}, 10 \mathrm{mmol} / \mathrm{l} \mathrm{Na}$-HEPES, $10 \mathrm{mmol} / \mathrm{l}$ D-glucose, $0.2 \mathrm{mmol} / 1 \mathrm{Cs}-\mathrm{EGTA}, 0.3 \mathrm{mmol} / \mathrm{l} \mathrm{GTP}$, $2 \mathrm{mmol} / \mathrm{l} \mathrm{Mg}$-ATP, $0.2 \mathrm{mmol} / \mathrm{l} \mathrm{cAMP}$ and $0.15 \%$ biocytin at pH 7.3 and 290-300 mOsm). Liquid junction potentials $(9 \mathrm{mV})$ were compensated. Maximum $\mathrm{Na}^{+}$ current amplitude, measured by increasing the magnitude of depolarizing pulse by $10 \mathrm{mV}$ increments, was mainly used to classify newborn GCs into three classes. Individual cell class was established from recording GFP-positive cells within the following range of days after virus injection: class 3 a 3 to $6 \mathrm{dpi}$; class 4 at 4 to $10 \mathrm{dpi}$ and class 5 at 6 to $44 \mathrm{dpi}$ (see Additional file 1D).

The stimulating electrode was placed near a recorded GC (Figure 2A) [26]. Response amplitude was adjusted as required for a minimal stimulation protocol to stimulate only one axon that was directly presynaptic to the recorded GC. Stimulus intensity was gradually increased from a low level until an EPSC suddenly appeared in an all or nothing manner (see Additional file 2). Single axons were stimulated at $0.1 \mathrm{~Hz}$, after checking that the mean EPSC amplitude for successful responses was not affected by small changes in stimulus intensity. Recordings were filtered at $10 \mathrm{kHz}$ (Filter 1) and $2.9 \mathrm{kHz}$ (Filter 2 ), digitized, and sampled at intervals of 20 to $450 \mu \mathrm{s}$ $(2.2-50 \mathrm{kHz})$ according to the requirements of individual protocols [12]. Series resistance $(<30 \mathrm{M} \Omega$ ) was monitored for stability throughout the recordings and if it had a change of $>20 \%$, the data were discarded. All experiments were performed in the presence of SR-95531 (gabazine) to block $\mathrm{GABA}_{\mathrm{A}}$ receptor-mediated currents.

Mean values from failure traces were subtracted from those of all responses (successes and failures) to measure response amplitude, $10-90 \%$ rise times, and decay time constants. Decay time was calculated by the formula:

$$
I(t)=I_{f} \exp \left(-t / t_{f}\right)+I_{s} \exp \left(-t / t_{s}\right),
$$

where $I_{f}$ and $I_{s}$ are the peak amplitudes of fast and slow components, respectively, and $t_{f}$ and $t_{s}$ are the corresponding time constants. For comparison, weighted mean decay time constants were calculated by:

$$
t_{w}=t_{f}\left[I_{f} /\left(I_{f}+I_{s}\right)\right]+t_{s}\left[I_{s} /\left(I_{f}+I_{s}\right)\right]
$$

To estimate single channel conductance, the mean current waveform was scaled to the peak of each synaptic current. The variance of each synaptic current around the scaled mean curve was then calculated. These variances were divided into 200 equally sized bins based on amplitude, and plotted against the mean current value within each scaled mean current bin. All data points were fitted by:

$$
\sigma^{2}-\sigma_{\text {basal }}^{2}=i * I-I^{2} / N
$$

Where $i$ is the current carried by a single open channel, and $N$ is the number of open channels. NMDARmediated EPSCs showed a skewed variance versus mean relationship. The single-channel conductance for NMDAR-mediated currents was estimated by fitting the initial slope of the relationship (Figure 3C). For AMPAR-mediated EPSCs, the variance versus mean relationship was parabolic. Single-channel conductance for AMPAR-mediated currents was therefore estimated using $i$, and the difference between holding potential and reversal potential (Figure 4C).

For paired-pulse stimulation, two consecutive stimuli were delivered with an inter-pulse interval of $50 \mathrm{~ms}$. The AMPAR-mediated EPSC amplitude was taken as the mean for all successes and failures (Figure 5; Figure 7), whereas potency was calculated from the mean successful responses only (Figure 6; Figure 7). The paired-pulse ratio was calculated as the mean EPSC response to the second pulse divided by mean EPSC response to first pulse (Figure 5; Figure 6; Figure 7). Simulated data were generated using a Poisson model: potency ratio:

$$
\left(E P S C_{2} / E P S C_{1}\right)=\left(\ln \left[1-S R_{2}\right] / \ln \left[1-S R_{1}\right]\right) *\left(S R_{1} / S R_{2}\right) .
$$

One or two slices were prepared from each virusinjected mouse and individual data were obtained from individual slices. Results are reported as mean \pm SEM. A paired $t$-test was used for statistical analysis (Figure 6C; Figure 7C; Additional file 4). Kruskal-Wallis test followed by the Dunn multiple comparison test were also used to evaluate the data.

\section{Immunohistochemistry}

Tissue slices containing biocytin-loaded cells were fixed in $4 \%$ paraformaldehyde at $4^{\circ} \mathrm{C}$ overnight. Slices were then washed three times in $0.1 \mathrm{~mol} / \mathrm{l}$ phosphate buffer $\mathrm{pH} 7.4$, without resectioning, and incubated with PBS containing Alexa 546 conjugated-Streptavidin (Molecular Probes, http://www.probes.invitrogen.com) and $0.25 \%$ Triton-X for 2 hours at room temperature. After washing three times in phosphate buffer, slices were observed under a confocal microscope (TCS SP5; Leica Wetzlar, Germany). 


\section{Pre-embedding EM immunocytochemistry}

Mice (7 dpi and $21 \mathrm{dpi}$ ) were anesthetized with pentobarbital and perfused with $2 \%$ PFA and $0.1 \%$ glutaraldehyde in sodium acetate buffer $\mathrm{pH} 6$ for 2 minutes followed by 1 hour perfusion with 2\% PFA and $0.1 \%$ glutaraldehyde in $0.1 \mathrm{~mol} / \mathrm{l}$ borate buffer $\mathrm{pH} 9$. Brains were post-fixed for $4 \mathrm{~h}$ with OBs cut into $70 \mu \mathrm{m}$ coronal sections on a vibrating blade microtome (VT1200; Leica). The sections were cryoprotected with $30 \%$ sucrose and freeze-thawed three times to enhance antibody penetration. Sections were then processed for immunoperoxidase using primary antibodies against GFP (1:20,000; Chemicon International, http://www.chemicon.com). The peroxidase reaction product was silver-intensified and gold-toned as described previously [70]. Serial thin sections were collected on copper slot grids and examined under a transmission electron microscope (JEM-1010; Jeol, Tokyo Japan) equipped with a side-mounted CCD camera (Mega View III, Olympus Soft Imaging Systems, Brandenburg Germany) at a magnification of 30,000. Synaptic contacts were analyzed in images taken from at least five consecutive sections. Glutamatergic (type 1) synapses were recognized by the presence of vesicles in the presynaptic terminal and by a prominent postsynaptic density (asymmetric junctions). Three-dimensional reconstructions were generated with the software Reconstruct (J.C. Fiala, Biology Department, Boston University, Boston, USA), using digital images acquired from each serial section.

\section{Additional material}

Additional file 1: Supplementary Figure 1: Classification of developing adult-generated granule cells (GCs). (A) Relationship between length of apical dendrite and maximal $\mathrm{Na}^{+}$current evoked by a depolarizing step pulse. Adult-born GCs were classified according to $\mathrm{Na}^{+}$ current amplitude, with white, gray and black circles representing classes 3, 4 and 5, respectively. Apical dendrites elongated during maturation. (B) Inverse correlation between the input membrane resistance $\left(R_{\text {in }}\right)$ and maximum $\mathrm{Na}^{+}$current amplitude evoked by a depolarizing step pulse. (C) Plots of maximum $\mathrm{Na}^{+}$current amplitude evoked by a depolarizing voltage step versus days post-injection (dpi) of virus. (D) Records from various newborn GCs after viral injection. Note the absence of clear boundaries among classes.

Additional file 2: Supplementary Figure 2: Proximal synaptic responses evoked by minimal stimulation. Gradually increasing stimulus intensity abruptly evoked events in an all-or-none manner. Open and closed circles indicate response success and failure, respectively. Unitary response amplitude was confirmed to be constant by a small increase in the stimulus intensity.

Additional file 3: Supplementary Figure 3: Developmental change of 3-hydroxy-5-methyl-4-isoxazolepropionic acid receptor (AMPAR)mediated outward currents at depolarized membrane potentials. (A) Typical traces. After AMPAR-mediated and N-methyl D-aspartate receptor (NMDAR)-mediated currents were recorded at the holding potential of +40 mV, 2,3-dioxo-6-nitro-1,2,3,4-tetrahydrobenzo[f]quinoxaline-7sulfonamide (NBQX) was applied to obtain NMDAR-mediated excitatory postsynaptic currents (EPSCs). Traces were derived from the subtraction of NMDAR-mediated EPSCS from AMPAR-mediated and NMDARmediated currents. Scale bar $=1 \mathrm{~ms}$ and $1 \mathrm{pA}$. (B) The amplitude of AMPAR-mediated EPSCs was much higher in class 5 than in class 3 cells (class 3: $1.43 \pm 0.43$; class 4: $1.52 \pm 0.34$; class 5: $7.69 \pm 3.15$ ) (class 3 versus class $5,{ }^{*} P<0.05$ ) (class 3 : six slices, six mice; class 4 : eight slices, eight mice; class 5 : four slices, four mice).

Additional file 4: Supplementary Figure 4: $\mathrm{Ca}^{2+}$-permeable AMPARs in class 3 GCs. (A) (Black) AMPAR-mediated EPSCs at the holding potential of $-70 \mathrm{mV}$ (red). This trace shows predicted data, obtained by inversion of the trace shown in black and multiplication by foursevenths. (B) (Green) AMPAR-mediated and NMDAR-mediated EPSCS at the holding potential of $+40 \mathrm{mV}$. (Pink) NMDAR-mediated EPSCs at the same holding potential. This current was recorded in the presence of NBQX. (Blue) AMPAR-mediated current at the holding potential of +40 $\mathrm{mV}$. This experimental trace was generated by subtracting the NMDARmediated component from both receptor-mediated currents (Green minus pink). (C) Comparison between the predicted and experimental traces. (A-C) Scale bar $=1 \mathrm{~ms}$ and $2 \mathrm{pA}$. (D) The maximum amplitude of the trace obtained from dividing experimental values by predicted values. If AMPAR-mediated EPSCs in class $3 \mathrm{GCs}$ are mediated by $\mathrm{Ca}^{2}$ ${ }^{+}$-impermeable AMPARs, this ratio would be equal to 1 (dashed line), given the linear current-voltage relationship of $\mathrm{Ca}^{2+}$-impermeable AMPAR. The experimental values obtained were significantly lower than the predicted values (class 3: six slices; ${ }^{*} P<0.05$ ).

Additional file 5: Supplementary Figure 5: Axon terminals make contacts with both adult-born and pre-existing GCs. A large axon terminal (Ax: red) makes two synapses with a GFP-positive dendrite (GC at 7 days post-injection: green) and a GFP-negative dendrite (a presumptive pre-existing GC: blue). Arrows point to the postsynaptic density. Note that the synapse onto the GFP-positive profile has a complex morphology and shows clear perforation. Scale bar $=50 \mathrm{~nm}$.

\section{Acknowledgements}

This work was supported by the Fondation pour la Recherche Médicale "Equipe FRM", the Groupe "Novalis-Taitbout" and the Ecole des Neurosciences de Paris (ENP), Compagnia di San Paolo and Regione Piemonte (Ricerca Sanitaria Finalizzata 2006 and 2008). HK was supported by the Association Pasteur-Japon fellowship. MP is the recipient of a doctoral fellowship from 'Università Italo-Francese' (Progetto Vinci) and Servier. The laboratory is also supported by the Agence Nationale de la Recherche "ANR09-NEUR-004" in the frame of "ERA-NET NEURON" of FP7 program by the European Commission. Dr. Lledo's visit to the Department of Molecular and Cellular Biology, Harvard University (Murthy's laboratory), was funded by the Philippe Foundation.

\section{Author details}

'Laboratory for Perception and Memory, Institut Pasteur, Paris, France. ${ }^{2}$ Centre National de la Recherche Scientifique (URA 2182), 25 rue du Dr. Roux, F-75724 Paris, France. ${ }^{3}$ Department of Anatomy, Pharmacology and Forensic Medicine and National Institute of Neuroscience-Italy, University of Turin, Italy

\section{Authors' contributions}

HK contributed to the concept, designed, performed the electrophysiological experiments and analyzed the data. MP and AN performed morphological and electrophysiological experiments, respectively. KM prepared lentiviruses. HK, MS-P and P-ML. wrote the manuscript.

\section{Competing interests}

The authors declare that they have no competing interests.

Received: 9 September 2010 Accepted: 1 November 2010 Published: 1 February 2011

\section{References}

1. Abrous DN, Koehl M, Le Moal M: Adult neurogenesis: from precursors to network and physiology. Physiol Rev 2005, 85:523-569. 
2. Ming $\mathrm{GL}$, Song $\mathrm{H}$ : Adult neurogenesis in the mammalian central nervous system. Annu Rev Neurosci 2005, 28:223-250.

3. Duan X, Kang E, Liu CY, Ming GL, Song H: Development of neural stem cell in the adult brain. Curr Opi Neurobiol 2008, 18:108-115.

4. Lledo PM, Merkle FT, Alvarez-Buylla A: Origin and function of olfactory bulb interneuron diversity. Trends Neurosci 2008, 31:392-400.

5. Luskin MB: Restricted proliferation and migration of postnatally generated neurons derived from the forebrain subventricular zone. Neuron 1993, 11:173-189.

6. Lois C, Alvarez-Buylla A: Long-distance neuronal migration in the adult mammalian brain. Science 1994, 264:1145-1148.

7. Brill MS, Ninkovic J, Winpenny E, Hodge RD, Ozen I, Yang R, Lepier A, Gascón S, Erdelyi F, Szabo G, Parras C, Guillemot F, Frotscher M, Berninger B, Hevner RF, Raineteau O, Götz M: Adult generation of glutamatergic olfactory bulb interneurons. Nat Neurosci 2009, 12:1524-1533.

8. Carleton A, Petreanu LT, Lansford R, Alvarez-Buylla A, Lledo PM: Becoming a new neuron in the adult olfactory bulb. Nat Neurosci 2003, 6:507-518.

9. Belluzzi O, Benedusi M, Ackman J, LoTurco JJ: Electrophysiological differentiation of new neurons in the olfactory bulb. J Neurosci 2003, 23:10411-10418

10. Mizrahi A: Dendritic development and plasticity of adult-born neurons in the mouse olfactory bulb. Nat Neurosci 2007, 10:444-452.

11. Whitman MC, Greer CA: Synaptic integration of adult-generated olfactory bulb granule cells: basal axodendritic centrifugal input precedes apical dendrodendritic local circuits. J Neurosci 2007, 27:9951-9961.

12. Grubb MS, Nissant A, Murry K, Lledo PM: Functional maturation of the first synapse in olfaction: development and adult neurogenesis. J Neurosci 2008, 28:2919-2932.

13. Kelsch W, Lin CW, Lois C: Sequential development of synapses in dendritic domains during adult neurogenesis. Proc Natl Acad Sci 2008, 105:16803-16808.

14. Chen WR, Greer CA: Olfactory bulb. In The synaptic Organization of the Brain. 5 edition. Edited by: Shepherd GM. New York: Oxford University Press; 2004:165-216

15. Lledo PM, Alonso M, Grubb MS: Adult neurogenesis and functional plasticity in neuronal circuits. Nat Rev Neurosci 2006, 7:179-193.

16. Laaris N, Puche A, Ennis M: Complementary postsynaptic activity patterns elicited in olfactory bulb by stimulation of mitral/tufted and centrifugal fiber inputs to granule cells. J Neurophysiol 2007, 97:296-306.

17. Balu R, Pressler RT, Strowbridge BW: Multiple modes of synaptic excitation of olfactory bulb granule cells. J Neurosci 2007, 27:5621-5632.

18. Rall W, Shepherd GM, Reese TS, Brightman MW: Dendrodendritic synaptic pathway for inhibition in the olfactory bulb. Exp Neurol 1966, 14:44-56

19. Price JL, Powell TP: The synaptology of the granule cells of the olfactory bulb. J Cell Sci 1970, 7:125-155.

20. Price JL, Powell TP: An electron-microscopic study of the termination of the afferent fibres to the olfactory bulb from the cerebral hemisphere. J Cell Sci 1970, 7:157-187.

21. Orona E, Rainer EC, Scott JW: Dendritic and axonal organization of mitral and tufted cells in the rat olfactory bulb. J Comp Neurol 1984, 226:346-356.

22. de Olmos J, Hardy H, Heimer L: The afferent connections of the main and the accessory olfactory bulb formations in the rat: an experimental HRPstudy. J Comp Neurol 1978, 181:213-244.

23. Haberly $L B$, Price $J L$ : Association and commissural fiber systems of the olfactory cortex of the rat. J Comp Neurol 1978, 178:711-740.

24. Shipley MT, Adamek GD: The connections of the mouse olfactory bulb: a study using orthograde and retrograde transport of wheat germ agglutinin conjugated to horseradish peroxidase. Brain Res Bull 1984, 12:669-688.

25. Gao Y, Strowbridge BW: Long-term plasticity of excitatory inputs to granule cells in the rat olfactory bulb. Nat Neurosci 2009, 12:731-733.

26. Nissant A, Bardy C, Katagiri H, Murray K, Lledo PM: Adult neurogenesis promotes synaptic plasticity in the olfactory bulb. Nat Neurosci 2009, 12:728-730.

27. Hinds JW, Hinds PL: Synapse formation in the mouse olfactory bulb. I. Quantitative studies. J Comp Neurol 1976, 69:15-40.

28. Hinds JW, Hinds PL: Synapse formation in the mouse olfactory bulb. II. Morphogenesis. J comp Neurol 1976, 69:41-61.
29. Petreanu L, Alvarez-Buylla A: Maturation and death of adult-born olfactory bulb granule neurons: role of olfaction. J Neurosci 2002, 22:6106-6113.

30. Panzanelli P, Bardy C, Nissant A, Pallotto M, Sassoè-Pognetto M, Lledo PM, Fritschy JM: Early synapse formation in developing interneurons of the adult olfactory bulb. J Neurosci 2009, 29:15039-15052.

31. Takahashi T: Postsynaptic receptor mechanisms underlying developmental speeding of synaptic transmission. Neurosci Res 2005, 53:229-240.

32. Feldman DE, Knudsen El: Experience-dependent plasticity and the maturation of glutamatergic synapses. Neuron 1998, 20:1067-1071.

33. Yashiro K, Philpot BD: Regulation of NMDA receptor subunit expression and its implication for LTD, LTP and metaplasticity. Neuropharmacology 2008, 55:1081-1094.

34. Barrera NP, Edwardson JM: The subunit arrangement and assembly of ionotropic receptors. Trends Neurosci 2008, 31:569-576.

35. Traynelis SF, Silver RA, Cull-Candy SG: Estimated conductance of glutamate receptor channels activated during EPSCs at the cerebellar mossy fiber-granule cell synapses. Neuron 1993, 11:279-289.

36. Katagiri $H$, Fagiolini $M$, Hensch TK: Optimization of somatic inhibition at critical period onset in mouse visual cortex. Neuron 2007, 53:805-812.

37. Zucker RS, Regehr WG: Short-term synaptic plasticity. Annu Rev Physiol 2002, 64:355-405.

38. Stevens CF, Wang Y: Facilitation and depression at single central synapses. Neuron 1995, 14:795-802.

39. Isaac JTR, Lüthi A, Palmer MJ, Anderson WW, Benke TA, Collingridge GL: An investigation of the expression mechanism of LTP of AMPA receptormediated synaptic transmission at hippocampal CA1 synapses using failures analysis and dendritic recordings. Neuropharmacology 1998, 37:1399-1410.

40. Palmer MJ, Isaac JTR, Collingridge GL: Multiple developmentally regulated expression mechanism of long-term potentiation at CA1 synapses. J Neurosci 2004, 24:4903-4911.

41. Davis BJ, Macrides F: The organization of centrifugal projections from the anterior olfactory nucleus, ventral hippocampal rudiment, and piriform cortex to the main olfactory bulb in the hamster: an autoradiographic study. J Comp Neurol 1981, 203:475-493.

42. Luskin MB, Price JL: The topographic organization of associational fibers of the olfactory bulb system in the rat, including centrifugal fibers to the olfactory bulb. J Comp Neurol 1983, 216:264-291.

43. Yamaguchi M, Mori K: Critical period for sensory experience-dependent survival of newly generated granule cells in the adult mouse olfactory bulb. Proc Natl Acad Sci USA 2005, 102:9697-9702.

44. Lin CW, Sim S, Ainsworth A, Okada M, Kelsch W, Lois C: Genetically increased cell-intrinsic excitability enhances neuronal integration into adult brain circuits. Neuron 2010, 65:32-39.

45. Platel JC, Dave KA, Bordey A: Control of neuroblast production and migration by converging GABA and glutamate signals in the postnatal forebrain. J Physiol 2008, 586:3739-3743.

46. Darcy DP, Isaacson JS: Calcium-permeable AMPA receptors mediate glutamatergic signaling in neural precursor cells of postnatal olfactory bulb. J Neurophysiol 2010, 103:1431-1437.

47. Koh DS, Geiger JR, Jonas P, Sakmann B: $\mathrm{Ca}(2+)$-permeable AMPA and NMDA receptors in basket cells of rat hippocampal dentate gyrus. $J$ Physiol 1995, 485:383-402.

48. Komuro $\mathrm{H}$, Kumada $\mathrm{T}: \mathrm{Ca}^{2+}$ transients control CNS neuronal migration. Cell Calcium 2005, 37:387-393.

49. Métin C, Denizot JP, Ropert N: Intermediate zone cells express calciumpermeable AMPA receptors and establish close contact with growing axons. J Neurosci 2000, 20:696-708.

50. Li Y, Mu Y, Gage FH: Development of neural circuits in the adult hippocampus. Curr Top Dev Biol 2009, 87:149-174.

51. Imayoshi I, Sakamoto M, Ohtsuka T, Takao K, Miyakawa T, Yamaguchi M, Mori K, Ikeda T, Itohara S, Kageyama R: Roles of continuous neurogenesis in the structural and functional integrity of the adult forebrain. Nat Neurosci 2008, 11:1153-1161.

52. Toni N, Teng EM, Bushong EA, Aimone JB, Zhao C, Consiglio A, van Praag H, Martone ME, Ellisman MH, Gage FH: Synapse formation on neurons born in the adult hippocampus. Nat Neurosci 2007, 10:727-734.

53. McAllister AK: Dynamic aspects of CNS synapse formation. Annu Rev Neurosci 2007, 30:425-450. 
54. Adesnik H, Li G, During MJ, Pleasure SJ, Nicoll RA: NMDA receptors inhibit synapse unsilencing during brain development. Proc Natl Acad Sci USA 2008, 105:5597-5602.

55. Flint AC, Maisch US, Weishaupt JH, Kriegstein AR, Monyer H: NR2A subunit expression shortens NMDA receptor synaptic currents in developing neocortex. J Neurosci 1997, 17:2469-2476.

56. Cull-Candy SG, Leszkiewicz DN: Role of distinct NMDA receptor subtypes at central synapses. SCi STKE 2004, 2004:re16.

57. Piña-Crespo JC, Gibb AJ: Subtypes of NMDA receptors in new-born rat hippocampal granule cells. J Physiol 2002, 541:4-64.

58. Vicini S, Wang JF, Li JH, Zhu WJ, Wang YH, Luo JH, Wolfe BB, Grayson DR: Functional and pharmacological differences between recombinant N-methyl-D-aspartate receptors. J Neurophysiol 1998, 79:555-566.

59. Momiyama A: Distinct synaptic and extrasynaptic NMDA receptors identified in dorsal form neurones of adult rat spinal cord. J Physiol 2000, 523:621-628.

60. Cline HT, Wu GY, Malinow R: In vivo development of neuronal structure and function. Cold Spring Harbor Symp Quant Biol 1996, 61:95-104.

61. Kerchner GA, Nicoll RA: Silent synapses and the emergence of a postsynaptic mechanism for LTP. Nat Rev Neurosci 2008, 9:813-825.

62. Wadiche Jl, Jahr CE: Multivesicular release at climbing fiber-Purkinje cell synapses. Neuron 2001, 32:301-313.

63. Oertner TG, Sabatini BL, Nimchinsky EA, Svoboda K: Facilitation at single synapses probed with optical quantal analysis. Nat Neurosci 2002, 5:657-664.

64. Redman S: Quantal analysis of synaptic potentials in neurons of the central nervous system. Physiol Rev 1990, 70:165-198.

65. Silver RA, Lubke J, Sakmann B, Feldmeyer D: High-probability uniquantal transmission at excitatory synapses in barrel cortex. Science 2003, 302:1981-1984.

66. Toni N, Buchs PA, Nikonenko I, Bron CR, Muller D: LTP promotes formation of multiple spine synapses between a single axon terminal and a dendrite. Nature 1999, 402:421-425.

67. Xu-Friedman MA, Regehr WG: Structural contributions to short-term plasticity. Physiol Rev 2004, 84:69-85.

68. Zhao C, Teng EM, Summers RGJr, Ming GL, Gage FH: Distinct morphological stages of dentate granule neuron maturation in the adult mouse hippocampus. J Neurosci 2006, 26:3-11.

69. Toni N, Laplagne DA, Zhao C, Lombardi G, Ribak CE, Gage FH, Schinder AF: Neurons born in the adult dentate gyrus form functional synapses with target cells. Nat Neurosci 2008, 11:901-907.

70. Sassoè-Pognetto $M$, Wässle $H$, Grünert U: Glycinergic synapses in the rod pathway of the rat retina: cone bipolar cells express the alpha 1 subunit of the glycine receptor. J Neurosci 1994, 14:5131-5146.

doi:10.1186/2042-1001-1-6

Cite this article as: Katagiri et al: Dynamic development of the first synapse impinging on adult-born neurons in the olfactory bulb circuit. Neural Systems \& Circuits 2011 1:6.

\section{Submit your next manuscript to BioMed Central and take full advantage of:}

- Convenient online submission

- Thorough peer review

- No space constraints or color figure charges

- Immediate publication on acceptance

- Inclusion in PubMed, CAS, Scopus and Google Scholar

- Research which is freely available for redistribution

Submit your manuscript at www.biomedcentral.com/submit
Biomed Central 